\section{Allergy $_{\mathrm{and}}$ Immunology}

Int Arch Allergy Immunol 2013;162:4 DOI: $10.1159 / 000351014$

Published online: June 27, 2013

\title{
Associate Editor A. Wesley Burks
}

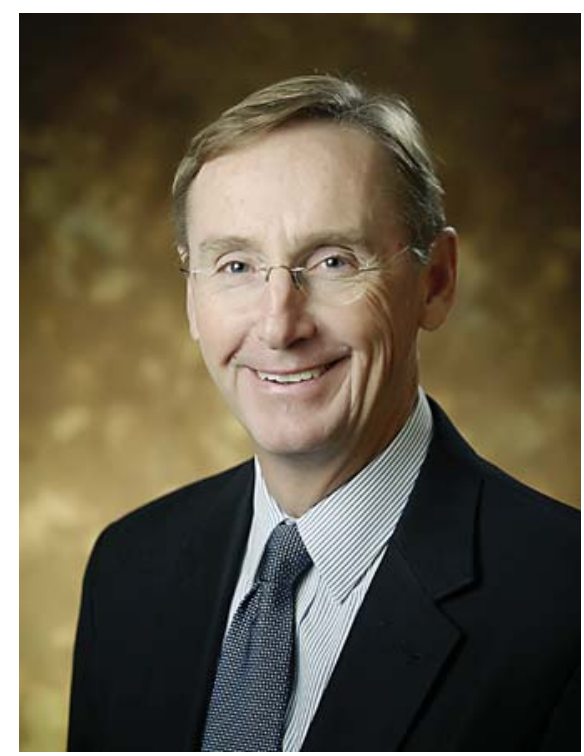

A. Wesley Burks, Chapel Hill, N.C.
A. Wesley Burks, MD, is the Curnen Distinguished Professor and Chief of the Department of Pediatrics at the North Carolina Children's Hospital in Chapel Hill, N. C.

Dr. Burks graduated from the University of Central Arkansas and later from the University of Arkansas for Medical Sciences. He completed a pediatric residency at the Arkansas Children's Hospital. Dr. Burks subsequently completed a fellowship in allergy and immunology medicine at Duke University Medical Center.

Dr. Burks' research interests are in the allergic diseases, particularly adverse reactions to foods. His work has centered on the molecular identification of the allergens in specific foods, a better understanding of the mechanism of adverse food reactions and the development of treatment for food allergy in animal models and clinical studies. He and his colleagues have several ongoing clinical studies with different types of mucosal and recombinant food proteins for immunotherapy. His laboratory funding comes from many sources, including the National Institutes of Health and private foundations.

Dr. Burks has published in many distinguished journals and has authored or coauthored numerous articles, chapters and abstracts. In addition, he serves on the editorial board for the Journal of Allergy and Clinical Immunology and the International Archives of Allergy and Immunology. He is a member of the NIH Hypersensitivity, Autoimmune, and Immune-mediated Diseases Study Section and currently serves as the Past President of the American Academy of Allergy, Asthma and Immunology. 